\section{ECONOMICS}

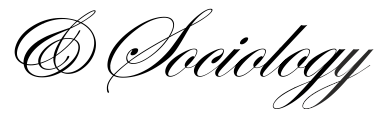

\title{
FACTORS INFLUENCING BELIEFS FORMATION TOWARDS THE ADOPTION OF SOCIAL COMMERCE IN SME TRAVEL AGENCIES
}

\author{
Mohammad Dalvi-Esfahani, \\ Higher Education Institute of Al- \\ Mahdi Mehr Isfahan, Isfahan, Iran \\ E-mail: \\ mohammaddalvi@hotmail.com \\ Hamed Shahbazi, \\ Faculty of Engineering, University \\ of Isfahan, Isfahan, Iran \\ E-mail:shabbazi@eng.ui.ac.ir \\ Mehrbakhsh Nilashi, \\ School of Computing, Faculty of \\ Engineering, Universiti Teknologi \\ Malaysia, Johor, Malaysia \\ E-mail:nilashidotne@@hotmail.com

\section{Sarminah Samad,} \\ CBA Research Centre, Collage of \\ Business and Administration, \\ Princess Nourah Bint \\ Abdulrahman University, Riyadh, \\ Saudi Arabia \\ E-mail: \\ sarminahsamad@hotmail.com
}

\author{
Abbas Mardani, \\ Azman Hashim International \\ Business School, \\ Universiti Teknologi Malaysia, \\ Skudai, Malaysia \\ E-mail:mabbas3@live.utm.my \\ Dalia Streimikiene, \\ Lithaunian Institute of Agrarian \\ Economcs instead of Litbuanian \\ Institute of Agricultural Economics, \\ Vilnius, Lithuania \\ E-mail:dalia.streimikiene@lei.lt
}

Received: February, 2018

1st Revision: March, 2018

Accepted: June, 2018

\begin{abstract}
The purpose of this study is to investigate the factors that influence beliefs formation towards the adoption of social commerce in SME travel agencies. Accordingly, a distal-proximal model is developed to study CEOs' beliefs towards the usefulness of social commerce. Data were collected through a questionnaire survey of travel agencies' CEOs in Isfahan, Iran. With 180 collected data from respondents, the Partial Least Squares-Structural Equation Modeling approach was taken to assess both measurement and structural models of the study. The results revealed that CEOs' innovativeness and attitude towards IT as individual factors, and organizational resources as institutional factor were significantly explained beliefs formation of respondents towards the usefulness of social commerce. However, it was found that the influences of CEOs' IT knowledge, subjective norms (professional peers, employees) and firm size on perceived usefulness were found insignificant. Implications of the study are further discussed.
\end{abstract}


DOI: $10.14254 / 2071-$

789X.2018/11-3/13

JEL Classification: D02, O17, P31
Keywords: social commerce, distal-proximal, travel agency, small and medium-sized enterprises

\section{Introduction}

Formulation of business strategies of several companies has been faced profound vicissitudes due to amalgamation of new technologies and innovative channels of communication and sales (Liébana-Cabanillas \& Alonso-Dos-Santos, 2017) and young customers can be referred to as the "handset generation" due to the use of various mobile shopping applications (Knežević \& Delić, 2017). In this regard, social media tools are utilized both for private users and businesses. Social media have altered the approach of relationship establishment in today's society (Zhang et al., 2014; Rutovic, 2016; Kot et al., 2017), including relationships among companies and their customers (Zhang \& Benyoucef, 2016). Accordingly, most leading electronic commerce (e-commerce) companies have been started to include Web 2.0 tools to their websites to help their customers to get in touch with other consumers, and hence, fostering their purchase intention behavior (Lu et al., 2016).

The term social commerce has been emerged amidst the proliferation of commercial use of social media tools (Curty \& Zhang, 2011; Cabelkova et al., 2015). The concept of social commerce has been described by Shen (as cited in Liébana-Cabanillas and AlonsoDos-Santos, 2017) in 2012 as "a new form of electronic commerce which involves a comprehensive approach to social media [...] with the purpose of providing assistance within the context of online buying and selling of products and services" (p. 2). In a broader sense, Zhou et al. (2013) argued that "social commerce involves the use of Internet-based media that allow people to participate in the marketing, selling, comparing, curating, buying, and sharing of products and services in both online and offline marketplaces, and in communities" (p. 61). By integrating user-generated content with storefronts, social commerce enables businesses to reach global customers efficiently. Hence, the importance of social commerce depends on its penetration as a novel platform of electronic commerce in the near future (Zhang \& Benyoucef, 2016).

Major drivers of economies in developing countries are small and medium-sized enterprises (SMEs) which are also considered as a source of employment (Abou-Shouk et al., 2016; Vojtovič, 2016; Dobeš et al., 2017; Pinkovetskaia, Nikitina \& Gromova, 2018; Pinkovetskaia \& Balynin, 2018). These types of firms are regarded as the foundation of entrepreneurial activities and a force for innovation (Widya-Hasuti et al. 2018; Ivanová \& Čepel, 2018), hence, SMEs are recognized as an imperative facilitator of new approaches in performing business operations development (Ongori, 2009, Chatzoglou \& Chatzoudes, 2016). Travel agencies, as one of the tourism-related SMEs, have increasingly utilized ecommerce capabilities to disseminate their tourism products in the marketplace (Wu and Chang, 2006, Tsai et al., 2005, Abou-Shouk et al., 2016; Strielkowski, 2017). E-commerce has converted travel agencies "from dependence on commission fees as their major revenue source to service charge collection" (Wu and Chang, 2006, p. 1253). Hence, travel agencies are trying to understand the impact of new technologies - social commerce - to their business, so they can make wise decisions regarding the adoption and diffusion of new technologies to sell and deliver their products and services to customers and further maintain relationships with them (Lin and $\mathrm{Fu}, 2012$ ). 
Although a number of studies (Grandon \& Pearson, 2004, Wu \& Chang, 2006, Soteriades et al., 2004, Seyal \& Rahman, 2003, Rahayu \& Day, 2015, Kurnia et al., 2015, Ghobakhloo et al., 2011, Hajli, 2013, Teh \& Ahmed, 2012, Hajli, 2015, Abou-Shouk et al., 2016) investigated the adoption of e-commerce and social commerce from the perspective of SMEs, few empirical studies have been conducted on how various factors impact beliefs of CEOs towards the use of social commerce in travel e-commerce industry.

Since the ultimate purpose of this study is to explore CEOs' beliefs, we have applied the distal-proximal approach in investigating the influence of various factors on the beliefs in technology use as the final dependent variable. Accordingly, the framework developed by Lewis et al. (2003) was applied in this study which posits that one's beliefs in technology use is shaped by various factors including individual, social and institutional factors.

The organization of the paper is as follows. Theoretical background of the study together with research hypotheses and proposed research model are provided in Section 2. Section 3 presents the methodology applied in this study. Results of the study are provided in Section 4 while discussions over the results are available in Section 5. Implications of the study are discussed in Section 6. Finally, Section 7 presents conclusion together with limitations of the study.

\section{Theoretical background}

\subsection{Distal-proximal framework}

Lewis et al. (2003) developed a framework which suggests that an individual's beliefs towards the use of technology are influenced by three dominant sources of influence including institutional influences, social influences and individual factors. The graphical representation of the framework is depicted in Figure 1.

According to this framework, beliefs towards technology use represent core dependent variable. Individual factors describe how a person's cognitive interpretation of information technology is linked to his/her cognition. IS literature have also demonstrated the importance of social influence on technology usage behavior. Moreover, IS research have long focused on how institutional factors influence one's behavior toward technology. It is agreed that institutional factors could significantly influence one's use of technology.

\subsection{Beliefs towards social commerce}

New technology is perceived by individuals from the perspective of their internal cognitive processes and developed beliefs towards that technology (Lewis et al., 2003). Technology acceptance model (TAM; Davis, 1989) and theory of reasoned action (TRA; Ajzen \& Fishbein, 1980), which are the two most dominant technology acceptance models in the IS literature, posit that individuals' beliefs mediate the influence of other variables towards the actual use of technology.

Considerable support is provided in the literature regarding the importance of beliefs in technology acceptance behavior. In general, perceived usefulness of technology has been recognized as one of the dominant predictors of technology usage behavior in prior studies (e.g., Wu and Chen, 2016, Akman and Mishra, 2015, Siamagka et al., 2015, Broman Toft et al., 2014, Pagani, 2006). Perceived usefulness postulates the extent to which an individual perceives how technology enhances performance (Davis et al., 1989). While numerous studies reported the significant impact of beliefs on usage behavior and behavioral intention, in this 
study we investigate the determinants of individuals' beliefs (i.e. perceived usefulness) as the final dependent variable in the model.

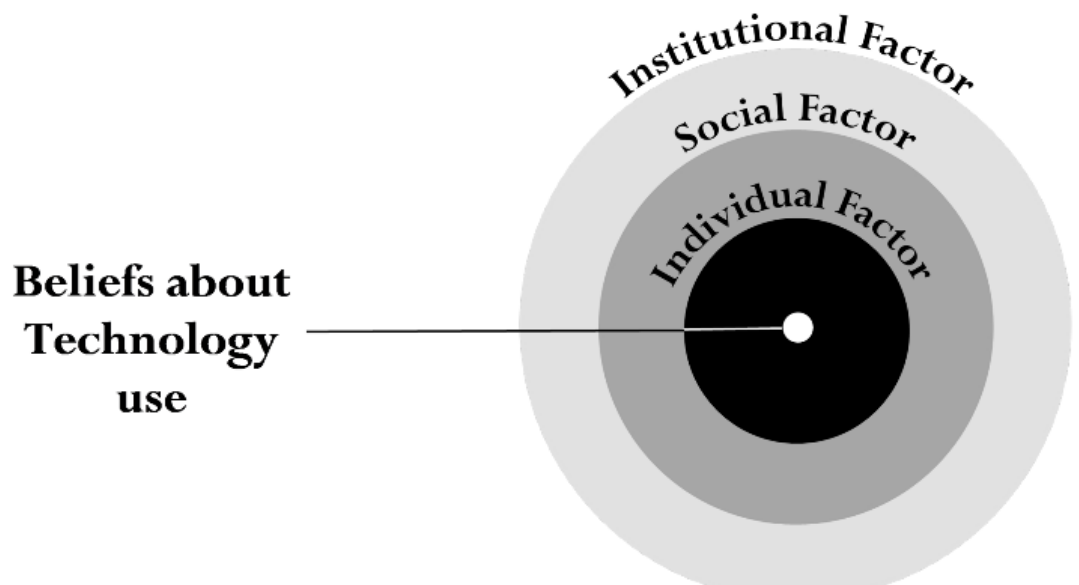

Figure 1. Distal-proximal framework (Source: Lewis et al., 2003, p. 659)

\subsection{Beliefs towards social commerce}

An organization's adoption and extension of a technology could be predicted by aspects such as CEO innovativeness, IT knowledge and attitudes toward IT adoption. In this regard, studies have shown that CEO innovativeness is positively linked to the adoption of innovation in recent years. In this regard, a study by Al-Qirim (2005) in New Zealand indicated that CEO innovativeness is linked to the adoption of e-commerce among SMEs. Furthermore, the important role played by the CEO innovative mindset was validated by Jantan et al. (2001). The study indicated that the innovativeness of Malaysian SMEs' CEOs is linked to the degree of technology adoption. Taking risks to try new technologies and observe things differently are considered as characteristics of innovative CEOs, which such personality would encourage them to allocate resources to try new innovations in their firms (Jantan et al., 2001). Agarwal and Prasad (1998) point out that innovative individuals are more inclined to use technology since they develop more positive beliefs towards the technology. Prior studies reported significant influence of innovativeness on perceived usefulness of technology (Liao et al., 2015).

Studies by Thong and Yap (1995), Kula and Tatoglu (2003) and Seyal and Rahman (2003) indicated a direct link between IT attitude with the acceptance of a firm's adoption of innovation. Specifically, Seyal and Rahman (2003) had statistically validated the significant and positive link between CEO attitude toward IT adoption with the adoption of e-commerce among SMEs in Brunei. The study revealed that, due to resource deficiency, managers of SMEs are required to demonstrate positive attitudes, as well better understanding on how strategically important electronic commerce is. In this light, Ramayah et al. (2016) reported that CEOs' attitudes towards IT adoption play a significant role in motivating SMEs' website continuance intention. CEOs with favorable attitudes, would be more open and receptive which drive them spend more time and money on activities related to online innovation, even though they are aware of the risks and uncertainties of internet use.

Previous studies indicated that organizational-level innovation is largely determined by the CEO's knowledge of IT (Hussein et al., 2007). The result of a study by Thong and Yap (1995) revealed that IT savvy CEOs would be more open to adopt innovative information technologies while Hussein et al. (2007) claimed in the Malaysian context, IT knowledge among managers has direct and positive effect on the success of IS implementation. In this 
regard, the level uncertainty in the adoption of IT adoption will be lessen by having more knowledge and less perceived risk of IT adoption. Accordingly, it can be suggested that CEOs with higher knowledge in IT would perceive the target technology useful to their businesses. Thus, following the abovementioned discussion we can hypothesize that:

H1: Innovativeness in information technology has a significant positive influence on travel agency's CEO's beliefs about the usefulness of social commerce.

H2: Attitude towards information technology has a significant positive influence on travel agency's CEO's beliefs about the usefulness of social commerce.

H3: Information technology knowledge has a significant positive influence on travel agency's CEO's beliefs about the usefulness of social commerce.

\subsection{Social factors}

IS literature demonstrated different conceptualizations and relevant operationalization of social influence. Subjective norm defined as the "perceived social pressure to perform or not perform the behavior" (Ajzen, 1991, p. 188) is a dominant conceptualization that is based on studies related to behavior models from the social psychological standpoint including theory of planned behavior (TPB; Ajzen, 1991) and TRA. The next conceptualization that emerges from the studies on communication technologies adoption and diffusion is based on the social information processing theory which illustrates how one's cognition on a specific technology is influenced by the information presented through one's social networks (Fulk, 1993). In this light, technology acceptance models have approached this construct placed differently despite the numerous instances on the significance of social influences. For instance, social influence is excluded in the conceptualization of TAM due to its ambiguous psychometric properties, meanwhile, past studies on TPB and TRA have shown that similar to attitude, social influence could affect usage behavior (e.g., Lai, 2017, Liobikienè et al., 2016, Lee, 2009). On the other hand, the latest expansion of the TAM model has shown that besides the effect of social influence on intention, it is also strongly linked to the perception of a technology's usefulness (Venkatesh $\&$ Bala, 2008). Furthermore, based on the theoretical arguments presented by Kelman (1958), it is suggested that social influence can affect the perceived usefulness of technology through the psychological pathways of identification and internalization. Through identification, believes and behaviors of influential individuals with power would influence one's believe and action, while the process of internalization occurs when a person considers a significant referent's view as part of his/her own believe. Individual characteristics, especially of the entrepreneur, has a positive influence on a decision to go international (Gonzalez-Peres et. al. 2018), also in the travel agency segment, which is more and more sensitive to the internationalization of economies, industries and firms. Hence, for the purpose of this study following hypotheses are developed:

H4: Perceived social influence from (a) professional peers and (b) employees has a significant positive influence on travel agency's CEO's beliefs about the usefulness of social commerce.

\subsection{Institutional factors}

Firm size and organizational resources are considered as important institutional factors influencing travel agencies' CEO's beliefs about social commerce (El-Gohary, 2012, ElGohary, 2011). Resource poverty commonly occurs to small businesses (Lepoutre \& Heene, 2006). A firm is experiencing resource poverty when they suffer problems such as high 
number of competitions, financial limitation, vulnerability to external forces, and the lack of professional expertise (Kroon et al., 2013). In this regard, small businesses are often portrayed as firms experiencing critical financial constraints, short-range management perspective and the lack of internal IT expertise. This creates more obstacles in their adoption of IT, making them less inclined to adopt IT (Thong et al., 1996). Prior studies suggested that larger firms are more inclined to adopt e-commerce (Al-Qirim, 2005, Ramayah et al., 2016, Ramdani \& Kawalek, 2007). Hence, it can be argued that in larger travel agencies (measured by number of employees) CEOs perceive social commerce more useful to their business strategies.

Comparative studies between developed and developing nations show that one of the prominent facilitators of the e-commerce adoption is organizational resources readiness. In a similar vein, there seems to be an emphasis on e-commerce adoption among SMEs in developing countries. In this light, a firm's views on the accessibility of financial/business, technological, and human resources is referred as organization resources (Molla and Licker, 2005). Organizational resources create the opportunity for business process improvement to business growth and adoption of technology (Ciabuschi et al., 2012). Several studies have demonstrated how e-commerce adoption can be determined by the availability of technological, financial and organizational resources (Kuan \& Chau, 2001, Kabanda \& Brown, 2017, Zhu \& Kraemer, 2005, Tan et al., 2007). Technological resources within an organization reflect availability of IT resources and further sophistication in their usage. Technological resources could affect the decision to adopt a technology as they can either ease or complicate new technology adoption (Kurnia et al., 2015). Meanwhile, capital availability to practice social commerce and further to perform activities related to social commerce refers to financial resources. Lastly, human resources are related to the availability of a knowledgeable and skilled human resources who can support and enhance business operations through the initialization and development of social commerce initiatives (Kurnia et al., 2015).

As aforementioned, CEOs of travel agencies with larger number of employees and availability of organizational resources would perceive social commerce more useful to their firms' business values. Hence, we can posit that:

H5: Firm size (number of employees) has a significant positive influence on travel agency's CEO's beliefs about the usefulness of social commerce.

H6: Availability of organizational resources has a significant positive influence on travel agency's CEO's beliefs about the usefulness of social commerce.

\section{Research model}

According to the discussion provided in previous sections, Figure 2 illustrates the research model of this study. According to this model, we hypothesized that perceived usefulness of social commerce by travel agencies' CEOs is influenced by individual factors (attitude, innovative, IT knowledge), social factors (subjective norms) and institutional factors (firm size, organizational resources). 


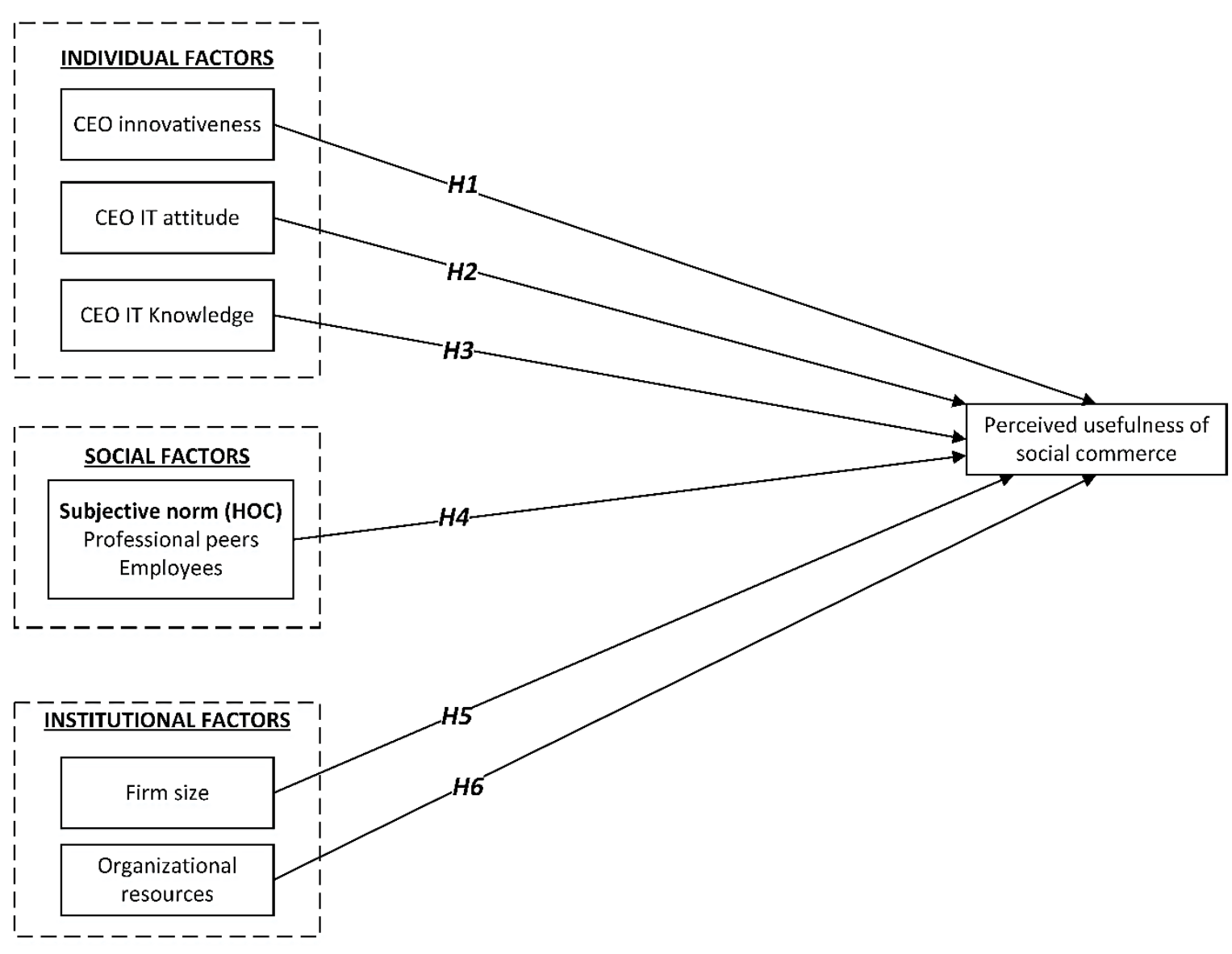

Figure 2. Research model

\section{Methodology}

\subsection{Measurement}

To measure constructs of the research model, relative items were adapted from previous studies which further were modified to suite the context of this study. All the measurement items of this study's constructs are developed reflectively except for the items of organizational resources constructs. Except for the firm size which was developed as a single-item construct (number of employees), other constructs were measured using a five point Likert scale ranging from 1 (strongly disagree) to 5 (strongly agree). Items to measure CEO innovativeness (three items) and CEO IT attitude (three items) were adapted from the study by Thong and Yap (1995). CEO IT knowledge (two items) was measured by the items retrieved from the study by Ghobakhloo et al. (2011) on e-commerce adoption by SMEs. Subjective norms of professional peers (two items) and subjective norms of employees (two items) were measured using the items retrieved from the study by Lewis et al. (2003). Organizational resources (three items) which was the only formative construct of the study was measured using the items developed by Kurnia et al. (2015). The construct firm size was measured by asking the respondents regarding the number of employees in their firms, according to the studies by Thong and Yap (1995) and Ramayah et al. (2016). Appendix A exhibits the measurement items of this study. 


\subsection{Sample and data collection}

For the purpose of this study, data were collected from travel agencies located in Isfahan as one of the most spectacular cities of Iran from the perspective of tourist attractions. Target respondents were CEOs who final decisions were made by them. To decide the sample size, we utilized the G*Power software with the settings recommended by Cohen (1992). The minimum required sample size was equal to 103 . Therefore, it was decided that data collection for the purpose of this study would be greater than the identified minimum required number.

In order to collect the data, an instrument was targeted at 300 CEOs and owners of travel agencies active in providing tourism services to tourists in Isfahan. After two weeks, a total of 180 completed questionnaires were received. As exhibited in Table 1, the majority of respondents were male (87\%), aged between 35-44 (44\%), undergraduate as their highest level of education (77\%) and had 5-20 employees (49\%).

\section{Data analysis}

The Partial Least Squares-Structural Equation Modeling (PLS-SEM) approach was incorporated to test the research model using the SmartPLS 3.0 software (Ringle et al., 2015). Following the two-stage analytical procedure proposed by Anderson and Gerbing (1988), the measurement and structural model of the research model was assessed. Accordingly, the measurement model was assessed for its indicator reliability, internal consistency, convergent and discriminant validity (Hair et al., 2013, Hair Jr and Hult, 2016). The structural model was assessed to examine the hypothesized relationships in the model. The bootstrapping method (with 5000 resamples) was applied to test the significance level of path coefficients (Hair et al., 2013, Hair et al., 2011).

\subsection{Common method bias}

Cross-sectional nature of the current study suggests the probability of existing common method bias (CMB). Accordingly, Harman's one-factor test (Podsakoff et al., 2003) and marker variable technique (Lindell and Whitney, 2001) were applied to assess CMB of the current study. The results of the analysis showed that the largest variance which was explained by a single factor was $36.4 \%$ indicting that the majority of the variance was not accounted by one factor (Podsakoff et al., 2003). To perform the marker variable technique, we have assigned all the items as the indicators of a new common method factor and further re-estimated the model. The results on analysis revealed that there was no positive correlation among the common method factor (i.e. marker variable) and the variables of the research model. Hence, common method bias issues were not detected in the present study.

\subsection{Measurement model assessment}

Reflective constructs of the measurement model were assessed for their indicator reliability, internal consistency and convergent validity by examining the values of outer loadings, composite reliability (CR) and average variance extracted (AVE), respectively (Hair et al., 2013). Suggested by Hair et al. (2013), the values of these assessment criterial should be outer loadings $>0.70, \mathrm{CR}>0.70$ and $\mathrm{AVE}>0.50$. For the formative construct (organizational resources), it was first examined regarding the collinearity of its indicators 
where the values of variance inflation factor (VIF) should be $0.20<\mathrm{VIF}<5$, then the relative importance of items' outer weights was assessed utilizing the bootstrapping procedure.

Based on the results exhibited in Table 2, all loadings were well-above the thresholds which indicated there was no issue regarding indicator reliability, internal consistency and convergent validity of reflective constructs.

To assess the discriminant validity, as suggested by Hair et al. (2013), the measurement model was assessed against Fornell-Larcker criteria. In this approach, the square root of AVE of each construct should be higher than its highest correlation with other constructs. Table 3 shows that there is no issue regarding convergent validity of reflective constructs as well.

Regarding the assessment of the only formative construct of the model, Table 4 exhibits that there is no issue regarding collinearity of indicators. Furthermore, utilizing bootstrapping method, we found that outer weights of all indicator items were significant.

Table 4 shows that there is no issue with the formative construct of the model and hence the developed measurement model of this study is valid and reliable to be used structural model assessment.

Table 1. Demographic attributes of respondents

\begin{tabular}{llll}
\hline \multicolumn{1}{l}{ Gender } & Frequency & Percent & Cumulative (\%) \\
\hline Male & & & \\
\hline \multicolumn{1}{l}{ Female } & 156 & 87 & 87 \\
\hline Age & 24 & 13 & 100 \\
\hline Below 25 & 3 & & \\
\hline $25-34$ & 43 & 24 & 2 \\
\hline $35-44$ & 79 & 44 & 70 \\
\hline 45-54 & 34 & 19 & 89 \\
\hline Above 55 & 21 & 11 & 100 \\
\hline Education level & & & \\
\hline Senior high school (or below) & 9 & 5 & 5 \\
\hline Undergraduate & 139 & 77 & 82 \\
\hline Postgraduate (or above) & 32 & 18 & 100 \\
\hline Company size (number of employees) & & & \\
\hline Less than 5 & 37 & 20 & 20 \\
\hline 5-20 & 88 & 49 & 69 \\
\hline 21-49 & 52 & 29 & 88 \\
\hline $50-99$ & 3 & 2 & 100 \\
\hline
\end{tabular}

Table 2. Measurement model assessment (indicator reliability, internal consistency, convergent validity)

\begin{tabular}{|c|c|c|c|c|}
\hline Construct & Items & $\begin{array}{l}\text { Outer } \\
\text { loading }\end{array}$ & $\begin{array}{l}\text { Composite } \\
\text { reliability }\end{array}$ & AVE \\
\hline \multirow{3}{*}{ CEO IT attitude } & CIA01 & 0.862 & \multirow[t]{3}{*}{0.890} & \multirow[t]{3}{*}{0.730} \\
\hline & CIA02 & 0.857 & & \\
\hline & CIA03 & 0.845 & & \\
\hline \multirow[t]{2}{*}{ CEO IT knowledge } & CIK01 & 0.821 & \multirow[t]{2}{*}{0.863} & \multirow[t]{2}{*}{0.760} \\
\hline & CIK02 & 0.920 & & \\
\hline CEO innovativeness & CIN01 & 0.838 & 0.881 & 0.712 \\
\hline
\end{tabular}




\begin{tabular}{|c|c|c|c|c|}
\hline & $\begin{array}{l}\text { CIN02 } \\
\text { CIN03 } \\
\end{array}$ & $\begin{array}{l}0.857 \\
0.836 \\
\end{array}$ & & \\
\hline Firm size & FSZ & 1.000 & 1.000 & 1.000 \\
\hline \multirow[t]{3}{*}{ Perceived usefulness } & PUS01 & 0.866 & \multirow[t]{3}{*}{0.894} & \multirow[t]{3}{*}{0.737} \\
\hline & PUS02 & 0.847 & & \\
\hline & PUS03 & 0.863 & & \\
\hline \multirow[t]{2}{*}{ Subjective norms: employees } & SNEM1 & 0.917 & \multirow[t]{2}{*}{0.904} & \multirow[t]{2}{*}{0.825} \\
\hline & SNEM2 & 0.900 & & \\
\hline \multirow{2}{*}{ Subjective norms: professional peers } & SNPP1 & 0.903 & \multirow{2}{*}{0.877} & \multirow[t]{2}{*}{0.780} \\
\hline & SNPP2 & 0.863 & & \\
\hline
\end{tabular}

Table 3. Measurement model assessment (discriminant validity)

\begin{tabular}{llllllll}
\hline & CIA & CIK & CIN & FSZ & PUS & SNPP & SNEM \\
\hline CEO IT attitude & $\mathbf{0 . 8 5 4}$ & & & & & & \\
\hline CEO IT knowledge & 0.344 & $\mathbf{0 . 8 7 2}$ & & & & & \\
\hline CEO innovativeness & 0.801 & 0.305 & $\mathbf{0 . 8 4 4}$ & & & & \\
\hline Firm size & -0.658 & -0.159 & -0.621 & $\mathbf{1 . 0 0 0}$ & & & \\
\hline Perceived usefulness & 0.826 & 0.305 & 0.828 & -0.691 & $\mathbf{0 . 8 5 9}$ & & \\
\hline Subjective norms: professional peers & 0.627 & 0.176 & 0.619 & -0.514 & 0.621 & $\mathbf{0 . 9 0 9}$ & \\
\hline Subjective norms: employees & 0.589 & 0.240 & 0.582 & -0.428 & 0.589 & 0.696 & $\mathbf{0 . 8 8 3}$ \\
\hline
\end{tabular}

Table 4. Assessment of the formative construct

\begin{tabular}{lllcccc}
\hline Construct & Item & VIF & $\begin{array}{c}\text { Outer } \\
\text { weight }\end{array}$ & $t$-value & $\begin{array}{c}\text { Significance } \\
\text { level }\end{array}$ & $p$-value \\
\hline Organizational resources & ORS01 & 1.881 & 0.481 & 7.059 & $*$ & 0.000 \\
\cline { 2 - 7 } & ORS02 & 1.837 & 0.405 & 6.078 & $*$ & 0.000 \\
\cline { 2 - 7 } & ORS03 & 1.603 & 0.282 & 4.235 & $*$ & 0.000 \\
\hline
\end{tabular}

$* p<0.001$ (one-tailed test)

\subsection{Structural model assessment}

The developed hypotheses in this study were assessed utilizing the bootstrapping method with 5000 resamples as suggested by Hair et al. (2013). The results of structural model assessment are illustrated in Figure 3 and presented in Table 5

Following the rules of thumb held forth by Hair et al. (2013), the $\mathrm{R}^{2}$ value of perceived usefulness of social commerce can be considered substantial. The results of the analysis showed that out of seven developed hypotheses, three hypotheses are significantly accepted while four of them are rejected. Hypothesis 1 posits that CEO innovativeness significantly determines perceived usefulness of social commerce within travel agencies. The results revealed that this relationship with the path coefficient of 0.326 is significant ( $t$-value $=4.935$, p-value $=0.000$ ), hence, hypothesis 1 is accepted. Hypothesis 2 suggested that CEO's attitude towards social commerce would influence perceived usefulness, where the results reported in Table $5(\beta=0.266, \mathrm{t}$-value $=3.324$, p-value $=0.000)$ confirms the acceptance of this hypothesis. The influence of CEO IT knowledge on perceived usefulness of social commerce which was suggested in hypothesis 3 was not supported in this study ( $\beta=$ 0.020 , t-value $=0.559, \mathrm{p}$-value $>0.05)$, and hence, hypothesis 3 is rejected. The influence of subjective norms was discussed in hypothesis 4 , but data analysis in this study showed that professional peers $(\mathrm{H} 4 \mathrm{a}, \beta=0.066$, $\mathrm{t}$-value $=1.381$, $\mathrm{p}$-value $>0.05)$ and employees $(\mathrm{H} 4 \mathrm{~b}, \beta=$ 
0.012, t-value $=0.241, \mathrm{p}$-value $>0.05)$ did not have impact on CEOs beliefs towards the usefulness of social commerce. Hence, hypothesis 4 was rejected. Hypothesis 5 discussed the impact of firm size (number of employees) on CEOs' perceived usefulness of social commerce in which it was rejected with the data collected in this study $(\beta=-0.165)$. The influence of firm size on perceived usefulness was negative which indicated that firms with fewer number of employees have CEO' with beliefs more towards usefulness of social commerce.

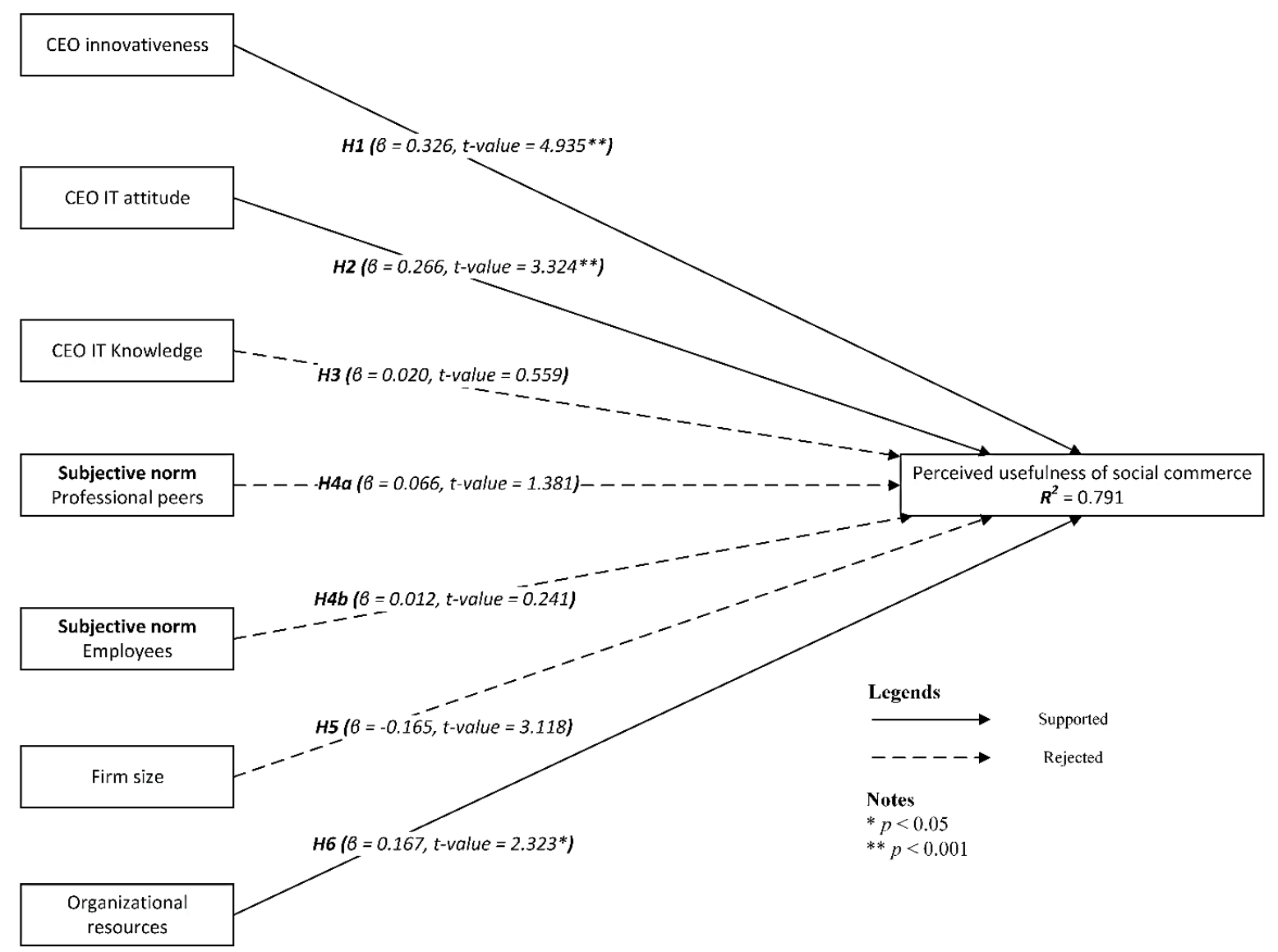

Figure 3. Structural model assessment

Finally, the impact of organizational resources on perceived usefulness was studied in the hypothesis 6 , in that it was significantly supported $(\beta=0.167$, t-value $=2.323$, p-value $=$ 0.010), and hence, hypothesis 6 was accepted.

Table 5. Structural model assessment results

\begin{tabular}{|c|c|c|c|c|c|c|}
\hline Hypothesis & Relationship & Path coefficient & $\overline{R^{2}}$ & $t$-value & Significance level & $p$-value \\
\hline H1 & $\mathrm{CIN} \rightarrow \mathrm{PUS}$ & 0.326 & & 4.935 & ** & 0.000 \\
\hline $\mathrm{H} 2$ & $\mathrm{CIA} \rightarrow$ PUS & 0.266 & & 3.324 & $* *$ & 0.000 \\
\hline $\mathrm{H} 3$ & CIK $\rightarrow$ PUS & 0.020 & & 0.559 & Not supported & 0.288 \\
\hline $\mathrm{H} 4 \mathrm{a}$ & SNPP $\rightarrow$ PUS & 0.066 & & 1.381 & Not supported & 0.084 \\
\hline $\mathrm{H} 4 \mathrm{~b}$ & SNEM $\rightarrow$ PUS & 0.012 & & 0.241 & Not supported & 0.405 \\
\hline H5 & $\mathrm{FSZ} \rightarrow \mathrm{PUS}$ & -0.165 & & 3.118 & Negative effect & 0.001 \\
\hline H6 & ORS $\rightarrow$ PUS & 0.167 & 0.791 & 2.323 & $*$ & 0.010 \\
\hline
\end{tabular}




\section{Discussion}

Performing commercial activities through social media should be an inherent part of every firms' marketing strategy and growth plan. Social commerce provides businesses the chance of interacting with their customers and target their audiences. Entrepreneurs can benefit social commerce by bringing their products to the notice of their customers, sell them and also gain benefit from the content generated by their customers. Due to the importance of social commerce to the firm's success in a competitive environment, this study investigated travel agencies' CEOs' beliefs towards the usefulness of social commerce. Accordingly, a research model was developed based on the distal-proximal framework proposed by Lewis et al. (2003). More specifically, the results of this study revealed that innovative CEOs with more positive attitudes towards IT and technology have more positive beliefs towards the usefulness of social commerce to their business and marketing activities. This finding corroborates with the findings of previous studies highlighting the importance of CEOs' innovativeness attitude towards IT in technology adoption (Ramayah et al., 2016, Al-Qirim, 2008, Seyal \& Rahman, 2003). Furthermore, beliefs towards the usefulness of social commerce were stronger within the firms with better resources. The model explained $79 \%$ of variance in the beliefs towards the usefulness of social commerce. Table 5 summarizes the structural model assessment results.

The results of study (see Figure 3) showed that two individual factors, innovativeness and attitude, are important in driving CEOs' beliefs towards the usefulness of social commerce within travel agencies. It suggests that travel agencies with more innovative CEOs have stronger beliefs towards the usefulness of social commerce. This finding is in line with prior studies in the literature on e-commerce adoption. Al-Qirim (2008) reported CEO's innovativeness as one of the important factors in determining intention towards e-commerce adoption. Also, Ghobakhloo et al. (2011) showed that SMEs with more innovative CEOs are more inclined towards the adoption of e-commerce. They argued that innovative CEOs "would prefer to apply distinctive and risk solutions such as IS that modify the structure in which the problems are generated" (Ghobakhloo et al., 2011, p. 1246). Today, travelers own smartphones who are mobile device connected locally and internationally. Hence, they expect travel agencies to be interactive, not static. Innovative CEOs of travel agencies would gain opportunities provided by Web 2.0 to develop interactive environment to their businesses. Yesil and Sozbilir (2013) reported that innovative behavior is more obvious in individuals with the personality trait of openness to experience. Hence, CEOs' with characteristics such as curiosity, intelligence and flexibility as the traits of openness to experience would perceive social commerce more useful to the business activities of their travel agencies. A reasonable explanation would be that those who allocate resources of the organization are the ones who influence the decision to adopt technology (Thong \& Yap, 1995). In travel agencies as tourism SMEs, main decisions are made by CEOs. Major decisions are the ones which are made what to do to gain or maintain the competitive edge. Social commerce adoption is one possible approach towards competitive edge. Hence, when CEOs perceive that social commerce is one of the best approaches to gain competitive advantage, their positive attitudes towards social commerce are formed.

As posited, organizational resources positively influenced perceived usefulness of social commerce within travel agencies. This finding is in line with the study conducted by Molla and Licker (2005) on e-commerce adoption. They have reported that, e-commerce adoption within South African SMEs would be occurred when resources of the organization, highlighted as human, business and technology resources, are positively supported. When travel agencies have sufficient resources such as adequate infrastructure, procedures to adopt social commerce, and trained employees in utilizing social media in business activities, 
beliefs towards the usefulness of social commerce would be developed within that firm. Organizational resources in this study was measured as a formative construct with the measurement items focusing on in-house IS skills, financial resources and technical resources. It can be argued that, the sample in which data were collected in this study had sufficient resources in spite of their size (number of employees), and hence, their beliefs were positively more towards the usefulness of social commerce.

On the other hand, some hypothesized relationships in this study were not supported with the data collected in this study. Surprisingly, CEOs' knowledge in IT which we believed it plays an important role in formation of beliefs towards the usefulness of social commerce was rejected. It contradicts with the findings of previous studies highlighting the importance of IT knowledge on technology adoption (Thong \& Yap, 1995, Chatzoglou \& Chatzoudes, 2016, Hussein et al., 2007). We believed that in travel agencies with CEOs owning greater IT knowledge and skills, uncertainties towards social commerce adoption and belief formation would be diminished. Here, it can be concluded that, travel agencies would perceive social commerce useful to their businesses despite depending on their CEO's IT knowledge.

Moreover, among the two sources of social influence posited in this study, none were related to perceived usefulness of social commerce. SMEs are the organizations recognized for the autonomy in which major decisions are made with their CEOs. Hence, traditional hierarchical structures which are observed in large organizations are diminished in such organizations. Hence, independence and democracy are two important defining characteristics of SMEs. Hence, it is not surprising that the messages emanating from employees of such organizations were not significant in shaping CEOs' beliefs about social commerce use. Likewise, the self-governance characteristic of SMEs tempers the influence of professional peers exerted on travel agencies regarding the use of social commerce.

The relationship among firm size and perceived usefulness of social commerce was found insignificant in this study. Regarding the relationship between firm size and innovation adoption, mixed results are reported in the literature (Leal-Rodríguez et al., 2015). While several studies reported larger firms are more opt to adopt innovative technologies (e.g., Oh et al., 2009, Chatzoglou \& Chatzoudes, 2016, Chuang et al., 2007, Peltier et al., 2012), finding of this study is in line with the ones that reported the rate of innovation adoption is greater in smaller firms (De Jong \& Marsili, 2006). Leal-Rodríguez et al. (2015) argued that smaller firms are more tend to be innovative since they have "greater flexibility, versatility, and capacity to adapt to environment" (p. 805). One possible explanation would be, although travel agencies suffer lack necessary resources and know-how to invest in innovations their smaller sizes in regard to larger firms gives them "more flexibility and independence from institutional bureaucracy" (Leal-Rodríguez et al., 2015, p. 805).

\section{Implications}

\subsection{Theoretical implications}

New context, new model and new findings are three theoretical contributions of this study to social commerce adoption literature. As for new context, limited studies investigated the adoption of social commerce within travel agencies as one of tourism SMEs. To bridge this knowledge gap, this study proposed a research model to explore belief formation towards the usefulness of social commerce in travel agencies.

With regard to new model, this study applied the distal-proximal framework proposed by Lewis et al. (2003). According to this framework, individual's beliefs towards technology acceptance are influenced by individual factors, social factors and institutional factors. Hence, 
by reviewing the literature CEO's innovativeness, attitude towards IT and CEO's IT knowledge were considered as individual factors. Messages from professional peers and employees were considered as social factors. Institutional factors were included firm size and organizational resources. Findings of the study revealed that, CEOs' beliefs towards the usefulness of social commerce were mainly explained innovative mindset of CEOs, attitude towards IT and organizational resources.

Moreover, related to new findings, results of this study can provide directions for further studies on social commerce adoption within tourism SMEs. Researchers are advised to investigate potential additional factors that may impact belief formation towards the adoption of social commerce by travel agencies. Researchers can integrate well-established technology acceptance theories with the framework applied in this study to unravel the acceptance of social commerce by SMEs.

\subsection{Practical implications}

Regarding practical implications, IT consultants, vendors and governmental agencies can benefit the findings of this study in promoting social commerce adoption within tourism SMEs. Accordingly, IT consultants and vendors are advised to target their business marketing to SMEs with innovative CEOs. Hence, they should look for innovative mindset indicators such as adoption of innovative technologies to enhance business processes, creative advertisements, and participations in exhibitions. For those CEOs who are adaptive and are less innovative, consultants and vendors should take steps to increase the awareness of such CEOs regarding benefits of social commerce which it can accomplished by education. Adaptive CEOs are those who prefer to adopt IT when they are sure that adopting that IT would enhance their businesses not just doing things differently. With a better understanding of social commerce and its benefits to business, CEOs would develop positive attitude towards the adoption of social commerce. Related to governmental agencies, their responsibility is to increase the literacy of IT among SMEs and other firms. Hence, this can be achieved by providing subsidized seminars and training programs on social media and its capabilities on enhancing business performance specifically designed for CEOs of SMEs active in tourism industry.

Iran is ranked 14th in the world in terms of internet users (Nasihatkon, 2016). In addition, with the registration rate of $53 \%$ of Iranians in social media site, the electronic marketing in tourism and hospitality has increased in recent years. In case of Iranian tourism, as social media have recently been very popular in Iran, the findings of this study will accordingly help the tourism SMEs in performing commercial activities through social media. In addition, the results will help the CEOs of SMEs to effectively use the social media as a marketing tool in attracting their customers and enhancing the business strategies and performance.

\section{Conclusion}

This study investigated beliefs formation towards the usefulness of social commerce within travel agencies from the lens of distal-proximal framework proposed by Lewis et al. (2003). The influence of three individual factors (CEOs' innovativeness, IT attitude, CEOs' IT knowledge), two social factors (professional peers, employees) and two institutional factors (firm size, organizational resources) were investigated on perceived usefulness of social commerce. Data were collected from 180 travel agencies doing their business in Isfahan, Iran. After analyzing data utilizing PLS-SEM method, it was revealed that 
innovativeness, IT attitude and organizational resources were explaining perceived usefulness significantly. However, it was found that IT knowledge of CEOs, subjective norms (professional peers and employees), and firm size were insignificant in predicting perceived usefulness. Despite the contributions of this study, it suffers from some limitations. First, limited factors were investigated in this study for each dimension in the framework which there may other potential individual, social and institutional determinants explaining beliefs formation towards social commerce adoption. Future research may examine this possibility. The second limitation of this study focuses on data collection method. In this study, data were collected quantitatively, while Brown and Russell (2007) collected their data both quantitatively and qualitatively. Hence, future studies should collect qualitative data by providing participants' opinions on the factors impacting their beliefs formation towards the usefulness of social commerce. In addition, the majority of the respondents of this study have been male, indicating that the sample can be gender-biased. Accordingly, it is highly suggested that, the future studies further investigate the role of gender on the beliefs formation towards the usefulness of social commerce within travel agencies. Finally, the last limitation of this study focuses on the generalizability. Since, data of this study were collected from travel agencies performing business in Iran as a developing country, the findings may not be applicable in another context. Hence, further studies are required to test the model in different national context including more developed countries. Despite these limitations, we believe that important determinants of beliefs formation towards the usefulness of social commerce were identified in this study. Findings of this study provides implications both for literature on social commerce adoption and practices in this context.

\section{References}

Abou-Shouk, M. A., Lim, W. M. \& Megicks, P. (2016). Using competing models to evaluate the role of environmental pressures in ecommerce adoption by small and medium sized travel agents in a developing country. Tourism Management, 52, 327-339.

Agarwal, R. \& Prasad, J. (1998). A conceptual and operational definition of personal innovativeness in the domain of information technology. Information systems research, 9, 204-215.

Ajzen, I. \& Fishbein, M. (1980). Understanding attitudes and predicting social. Behaviour. Englewood Cliffs, NJ: Prentice-Hall.

Ajzen, I. (1991). The theory of planned behavior. Organizational behavior and human decision processes, 50, 179-211.

Akman, I. \& Mishra, A. (2015). Sector diversity in Green Information Technology practices: Technology Acceptance Model perspective. Computers in Human Behavior, 49, 477 486.

Al-Qirim, N. (2005). An Empirical Investigation of an e-commerce Adoption-Capability Model in Small Businesses in New Zealand. Electronic Markets, 15, 418-437.

Al-Qirim, N. (2008). The adoption of eCommerce communications and applications technologies in small businesses in New Zealand. Electronic Commerce Research and Applications, 6, 462-473.

Anderson, J. C. \& Gerbing, D. W. (1988). Structural equation modeling in practice: A review and recommended two-step approach. Psychological bulletin, 103, 411.

Broman Toft, M., Schuitema, G. \& Thøgersen, J. (2014). Responsible technology acceptance: Model development and application to consumer acceptance of Smart Grid technology. Applied Energy, 134, 392-400. 
Brown, I. \& Russell, J. (2007). Radio frequency identification technology: An exploratory study on adoption in the South African retail sector. International journal of information management, 27, 250-265.

Cabelkova, I., Strielkowski, W., \& Mirvald, M. (2015). Business influence on the mass media: A case study of 21 countries. Transformations in business \& economics, 14(1). 65-75.

Chatzoglou, P. \& Chatzoudes, D. (2016). Factors affecting e-business adoption in SMEs: an empirical research. Journal of Enterprise Information Management, 29, 327-358.

Chuang, T.-T., Rutherford, M. W. \& Lin, B. (2007). Owner/manager characteristics, organisational characteristics and IT adoption in small and medium enterprises. International Journal of Management and Enterprise Development, 4, 619-634.

Ciabuschi, F., Perna, A. \& Snehota, I. (2012). Assembling resources when forming a new business. Journal of Business Research, 65, 220-229.

Cohen, J. (1992). A Power Primer. Psychological bulletin, 112, 155-519.

Curty, R. G. \& Zhang, P. (2011). Social commerce: Looking back and forward. Proceedings of the Association for Information Science and Technology, 48, 1-10.

Davis, F. D. (1989). Perceived usefulness, perceived ease of use, and user acceptance of information technology. MIS quarterly, 319-340.

Davis, F. D., Bagozzi, R. P. \& Warshaw, P. R. (1989). User acceptance of computer technology: a comparison of two theoretical models. Management science, 35, 9821003.

De Jong, J. P. \& Marsili, O. (2006). The fruit flies of innovations: A taxonomy of innovative small firms. Research policy, 35, 213-229.

Dobeš, K., Kot, S., Kramoliš, J., Sopková, G. (2017). The Perception of Governmental Support in The Context of Competitiveness of SMEs in the Czech Republic. Journal of Competitiveness, 9(3), 34-50.

El-Gohary, H. (2011). e-marketing: Towards a Conceptualisation of a New Marketing Philosophy. Innovations in SMEs and conducting e-business: Technologies, trends and solutions. IGI Global.

El-Gohary, H. (2012). Factors affecting E-Marketing adoption and implementation in tourism firms: An empirical investigation of Egyptian small tourism organisations. Tourism management, 33, 1256-1269.

Fulk, J. (1993). Social construction of communication technology. Academy of Management journal, 36, 921-950.

Ghobakhloo, M., Arias-Aranda, D. \& Benitez-Amado, J. (2011). Adoption of e-commerce applications in SMEs. Industrial Management \& Data Systems, 111, 1238-1269.

Gonzalez-Perez, M., Velez-Ocampo, J., \& Herrera-Cano, C. (2018). Entrepreneurs' Features Affecting the Internationalisation of Service SMEs. Entrepreneurial Business and Economics Review, 6(2), 9-28. doi: https://doi.org/10.15678/EBER.2018.060201

Grandon, E. E. \& Pearson, J. M. (2004). Electronic commerce adoption: An empirical study of small and medium US businesses. Information \& management, 42, 197-216.

Hair , J. F., Hult, G. T. M., Ringle, C. \& Sarstedt, M. (2013). A primer on partial least squares structural equation modeling (PLS-SEM), Los Angeles, US, Sage Publications.

Hair Jr, J. F. \& Hult, G. T. M. (2016). A primer on partial least squares structural equation modeling (PLS-SEM), Sage Publications.

Hair, J. F., Ringle, C. M. \& Sarstedt, M. (2011). PLS-SEM: Indeed a silver bullet. The Journal of Marketing Theory and Practice, 19, 139-152.

Hajli, M. (2013). A research framework for social commerce adoption. Information Management \& Computer Security, 21, 144-154. 
Hajli, N. 2015. Social commerce constructs and consumer's intention to buy. International Journal of Information Management, 35, 183-191.

Hussein, R., Karim, N. S. A., Mohamed, N. \& Ahlan, A. R. (2007). The influence of organizational factors on information systems success in e-government agencies in Malaysia. The Electronic Journal of Information Systems in Developing Countries, 29.

Yesil, S. \& Sozbilir, F. (2013). An Empirical Investigation into the Impact of Personality on Individual Innovation Behaviour in the Workplace. Procedia - Social and Behavioral Sciences, 81, 540-551.

Ivanová, E. \& Čepel, M. (2018). The Impact of Innovation Performance on the Competitiveness of the Visegrad 4 Conutries. Journal of Competitiveness, 10(1), 54-72.

Jantan, M., Ramayah, T., Ismail, N. \& Salehudin, A. (2001). The CEO and AMT adoption in Malaysian small and medium scale manufacturing industries. Proceedings of the International Conference on Information Technology, Lausanne, Switzerland.

Kabanda, S. \& Brown, I. (2017). A structuration analysis of Small and Medium Enterprise (SME) adoption of E-Commerce: The case of Tanzania. Telematics and Informatics, 34, 118-132.

Kelman, H. C. (1958). Compliance, identification, and internalization three processes of attitude change. Journal of Conflict Resolution, 2, 51-60.

Knežević, B., \& Delić, M. (2017). Young Consumers' Perception of Problems and Usefulness of Mobile Shopping Applications. Entrepreneurial Business and Economics Review, 5(1), 43-58. doi: https://doi.org/10.15678/EBER.2017.050103

Kot, S., Tan, M., Dragolea, L. (2017), The Use of Social Media Supporting Studying, Economics and Sociology, 10(1), 169-180. doi:10.14254/2071-789X.2017/10-1/12

Kroon, B., Van De Voorde, K. \& Timmers, J. (2013). High performance work practices in small firms: a resource-poverty and strategic decision-making perspective. Small Business Economics, 41, 71-91.

Kuan, K. K. \& Chau, P. Y. (2001). A perception-based model for EDI adoption in small businesses using a technology-organization-environment framework. Information \& management, 38, 507-521.

Kula, V. \& Tatoglu, E. (2003). An exploratory study of Internet adoption by SMEs in an emerging market economy. European Business Review, 15, 324-333.

Kurnia, S., Choudrie, J., Mahbubur, R. M. \& Alzougool, B. (2015). E-commerce technology adoption: A Malaysian grocery SME retail sector study. Journal of Business Research, 68, 1906-1918.

Lai, H.-J. (2017). Examining civil servants' decisions to use Web 2.0 tools for learning, based on the decomposed theory of planned behavior. Interactive Learning Environments, 25, 295-305.

Leal-Rodríguez, A. L., Eldridge, S., Roldán, J. L., Leal-Millán, A. G. \& Ortega-Gutiérrez, J. (2015). Organizational unlearning, innovation outcomes, and performance: The moderating effect of firm size. Journal of Business Research, 68, 803-809.

Lee, M.-C. (2009). Factors influencing the adoption of internet banking: An integration of TAM and TPB with perceived risk and perceived benefit. Electronic Commerce Research and Applications, 8, 130-141.

Lepoutre, J. \& Heene, A. (2006). Investigating the impact of firm size on small business social responsibility: A critical review. Journal of business ethics, 67, 257-273.

Lewis, W., Agarwal, R. \& Sambamurthy, V. (2003). Sources of influence on beliefs about information technology use: An empirical study of knowledge workers. MIS quarterly, 657-678. 
Liao, Y.-W., Huang, Y.-M., Chen, H.-C. \& Huang, S.-H. (2015). Exploring the antecedents of collaborative learning performance over social networking sites in a ubiquitous learning context. Computers in Human Behavior, 43, 313-323.

Liébana-Cabanillas, F. \& Alonso-Dos-Santos, M. (2017). Factors that determine the adoption of Facebook commerce: The moderating effect of age. Journal of Engineering and Technology Management.

Lin, S.-W. \& Fu, H.-P. (2012). Uncovering critical success factors for business-to-customer electronic commerce in travel agencies. Journal of travel \& tourism marketing, 29, 566584.

Lindell, M. K. \& Whitney, D. J. (2001). Accounting for common method variance in crosssectional research designs. Journal of applied psychology, 86, 114.

Liobikienè, G., Mandravickaitè, J. \& Bernatonienè, J. (2016). Theory of planned behavior approach to understand the green purchasing behavior in the EU: A cross-cultural study. Ecological Economics, 125, 38-46.

Lu, B., Fan, W. \& Zhou, M. (2016). Social presence, trust, and social commerce purchase intention: an empirical research. Computers in Human Behavior, 56, 225-237.

Molla, A. \& Licker, P. S. (2005). eCommerce adoption in developing countries: a model and instrument. Information \& management, 42, 877-899.

Nasihatkon, B., Kheiri, J., \& Miralbell, O. (2016). Social media and hotel e-marketing in Iran: The case of Parsian International Hotels. Turyzm, 26(2), 15-21.

Oh, K.-Y., Cruickshank, D. \& Anderson, A. R. (2009). The adoption of e-trade innovations by Korean small and medium sized firms. Technovation, 29, 110-121.

Ongori, H. (2009). Role of Information Communication Technologies Adoption in SMES: Evidence from Botswana. Research Journal of Information Technology, 1, 79-85.

Pagani, M. (2006). Determinants of adoption of high speed data services in the business market: evidence for a combined technology acceptance model with task technology fit model. Information \& Management, 43, 847-860.

Peltier, J. W., Zhao, Y. \& Schibrowsky, J. A. (2012). Technology adoption by small businesses: an exploratory study of the interrelationships of owner and environmental factors. International Small Business Journal, 30, 406-431.

Pinkovetskaia, I. S., Nikitina, I. N. \& Gromova, T. V. (2018). The Role of Small and Medium Entrepreneurship in the Economy of Russia. Montenegrin Journal of Economics, 14(3), 177-188.

Pinkovetskaia, I. S. \& Balynin, I. V. (2018). Structure of Small and Medium-Sized Business: Results of Total Statistic Observations in Russia. Montenegrin Journal of Economics, 14(1), 143-158.

Podsakoff, P. M., MacKenzie, S. B., Lee, J.-Y. \& Podsakoff, N. P. (2003). Common method biases in behavioral research: a critical review of the literature and recommended remedies. Journal of applied psychology, 88, 879.

Rahayu, R. \& Day, J. (2015). Determinant Factors of E-commerce Adoption by SMEs in Developing Country: Evidence from Indonesia. Procedia-Social and Behavioral Sciences, 195, 142-150.

Ramayah, T., Ling, N. S., Taghizadeh, S. K. \& Rahman, S. A. (2016). Factors influencing SMEs website continuance intention in Malaysia. Telematics and Informatics, 33, 150164.

Ramdani, B. \& Kawalek, P. (2007). SMEs \& IS innovations adoption: a review \& assessment of previous research. Academia. Revista Latinoamericana de Administración, 47-70.

Ringle, C. M., Wende, S. \& Becker, J.-M. (2015). SmartPLS 3. Boenningstedt: SmartPLS $\mathrm{GmbH}$, http://www.smartpls.com. 
Rutovic, Z. (2016). Economic aspects of media globalization. Journal of International Studies, 9(2), 233-243.

Seyal, A. H. \& Rahman, M. N. A. (2003). A preliminary investigation of e-commerce adoption in small \& medium enterprises in Brunei. Journal of Global Information Technology Management, 6, 6-26.

Siamagka, N.-T., Christodoulides, G., Michaelidou, N. \& Valvi, A. (2015). Determinants of social media adoption by B2B organizations. Industrial Marketing Management.

Soteriades, M., Aivalis, C. \& Varvaressos, S. (2004). E-marketing and E-commerce in the Tourism Industry: A Framework to Develop and Implement Business Initiatives. Tourism Today Tourism Today.

Strielkowski, W. (2017). Promoting Tourism Destination through Film-Induced Tourism: The Case of Japan. Trziste, 29(2), 193-203.

Tan, J., Tyler, K. \& Manica, A. (2007). Business-to-business adoption of eCommerce in China. Information \& management, 44, 332-351.

Teh, P.-L. \& Ahmed, P. K. Understanding social commerce adoption: An extension of the Technology Acceptance Model. Management of Innovation and Technology (ICMIT), 2012 IEEE International Conference on, 2012. IEEE, 359-364.

Thong, J. Y. \& Yap, C.-S. (1995). CEO characteristics, organizational characteristics and information technology adoption in small businesses. Omega, 23, 429-442.

Thong, J. Y., Yap, C.-S. \& Raman, K. (1996). Top management support, external expertise and information systems implementation in small businesses. Information systems research, 7, 248-267.

Tsai, H.-T., Huang, L. \& Lin, C.-G. (2005). Emerging e-commerce development model for Taiwanese travel agencies. Tourism Management, 26, 787-796.

Venkatesh, V. \& Bala, H. (2008). Technology acceptance model 3 and a research agenda on interventions. Decision sciences, 39, 273-315.

Vojtovič, S. (2016). The Impact of the Structural Funds on Competitiveness of Small and Medium-Sized Enterprises. Journal of Competitiveness, 8(4), 30-45.

Widya-Hasuti, A., Mardani, A., Streimikiene, D., Sharifara, A., \& Cavallaro, F. (2018). The Role of Process Innovation between Firm-Specific Capabilities and Sustainable Innovation in SMEs: Empirical Evidence from Indonesia. Sustainability, 10, 2244.

Wu, B. \& Chen, X. (2016). Continuance intention to use MOOCs: Integrating the technology acceptance model (TAM) and task technology fit (TTF) model. Computers in Human Behavior.

Wu, J.-J. \& Chang, Y.-S. (2006). Effect of transaction trust on e-commerce relationships between travel agencies. Tourism Management, 27, 1253-1261.

Zhang, H., Lu, Y., Gupta, S. \& Zhao, L. (2014). What motivates customers to participate in social commerce? The impact of technological environments and virtual customer experiences. Information \& Management, 51, 1017-1030.

Zhang, K. Z. \& Benyoucef, M. (2016). Consumer behavior in social commerce: A literature review. Decision Support Systems, 86, 95-108.

Zhou, L., Zhang, P. \& Zimmermann, H.-D. (2013). Social commerce research: An integrated view. Electronic commerce research and applications, 12, 61-68.

Zhu, K. \& Kraemer, K. L. (2005). Post-adoption variations in usage and value of e-business by organizations: cross-country evidence from the retail industry. Information systems research, 16, 61-84. 